\title{
Non-Diabetic Nephropathies among Diabetic Patients of the Nephrology Department of Dakar
}

\author{
Mame Selly Diawara ${ }^{*}$, M. M. Cisse1, N. Keita'2, Y. Kane' ${ }^{3}$, S. Mahmoud², A. T. Lemrabott², \\ M. A. Faye' ${ }^{2}$, S. Diagne ${ }^{2}$, F. Ka², A. Niang², B. Diouf ${ }^{2}$ \\ ${ }^{1}$ Nephrology Department of Regional Hospital of Thies, Thies, Senegal \\ ${ }^{2}$ Nephrology Department of Teaching Hospital Le Dantec, Dakar, Senegal \\ ${ }^{3}$ Nephrology Department of Regional Hospital of Zinguinchor, Zinguinchor, Senegal \\ Email: *mamindiouga79@yahoo.fr
}

How to cite this paper: Diawara, M.S., Cisse, M.M., Keita, N., Kane, Y., Mahmoud, S., Lemrabott, A.T., Faye, M.A., Diagne, S., Ka, F., Niang, A. and Diouf, B. (2019) Non-Diabetic Nephropathies among Diabetic Patients of the Nephrology Department of Dakar. Open Journal of Nephrology, 9, 41-48.

https://doi.org/10.4236/ojneph.2019.92005

Received: March 13, 2019

Accepted: April 15, 2019

Published: April 18, 2019

Copyright $\odot 2019$ by author(s) and Scientific Research Publishing Inc. This work is licensed under the Creative Commons Attribution International License (CC BY 4.0).

http://creativecommons.org/licenses/by/4.0/

\section{(c) (i) Open Access}

\begin{abstract}
Introduction: Diabetic nephropathy is the most common cause of kidney disease in diabetics. However, in some cases the clinical symptoms is not typical and nephropathy may be different from diabetic and require the use of renal biopsy (RB) which is not usually indicated unless non-diabetic nephropathy (NND) is suspected. The objective of this study was to evaluate the prevalence of non-diabetic nephropathy (NDN) among the diabetic patients and to analyse the different predictive factors of its occurrence. Patients and methods: It was a retrospective, descriptive and analytical study which is carried out at the nephrology department of Aristide Le DANTEC hospital of Dakar over a period of 60 months. Diabetics with suspected NDN diagnosis based on renal anomalie that is associated with a recent diabetes, Acute renal failure with rapid progress, Diabetic retinopathy's absence, and Extrarenal signs (cutaneous, digestive and articular) associated with an acute renal failure. Microscopic haematuria was included. The epidemiological, clinical, biological and histological parameters were collected and analysed using the SPSS, 3.5 version software. Results: Out of 34 biopsied diabetic patients, 12 had NDN that is a prevalence of $35,3 \%$. The average age was $49.88 \pm 4.15$ years, 0.78 for the sex-ratio and the mean duration of diabetes is $12.53 \pm 4.7$ years. Glomerular syndrome was found in 30 patients $(88.23 \%)$, vascular nephropathy syndrome in 3 patients $(8.82 \%)$ and tubule-interstitial nephropathy syndrome in only one patient (2.94\%). Diabetic retinopathy (DR) and microscopic haematuria (HU) respectively existed in 10 patients $(34 \%)$ and 15 patients (44. 12\%). The Kidney biopsy (KB) indications were renal abnormalities associated with recent diabetes, acute renal failure with rapid
\end{abstract}


progress, absence of DR, extrarenal signs associated with acute renal failure and microscopic haematuria. Twenty-two patients $(64.7 \%)$ had diabetic nephropathy $(\mathrm{DN})$ and 12 patients $(38.2 \%)$ presented a NDN. Predictive factors of NDN diagnosis were a shorter diabetes duration $(\mathrm{P}=0.0008)$, high blood pressure $(\mathrm{P}=0.0015)$ and absence of $\mathrm{DR}(\mathrm{P}=0.005)$. Conclusion: Our data show that kidney injury in a diabetic is not always diabetic nephropathy. The Kidney biopsy (KB) is often needed in order to adopt an effective management.

\section{Keywords}

Diabetes, Diabetic Nephropathy, Non-Diabetic Nephropathy, Dakar

\section{Introduction}

Generally, the diabetic nephropathy's diagnosis is easy if the diabetes evolved for more than 10 years, in the presence of degenerative complications and when the evolution is marked by a proteinuria which precedes the renal failure. However, the absence of neuropathy and diabetic retinopathy in the presence of renal markers should be suspected of non-diabetic nephropathy [1] [2], as well as renal failure with rapid progress and haematuria [3].

The prevalence of non-diabetic nephropathy among patients is relatively high and varies from $20 \%$ to $37.5 \%$ [4]. According to the studies, nephrosclerosis is the most frequent nephropathy. To our knowledge this work has never been done in Senegal and the objectives were to:

- To assess the prevalence of non-diabetic nephropathy in diabetics;

- To analyse the different predictive clinical and Paraclinical diagnosis parameters of non-diabetic nephropathy in diabetics.

\section{Patients and Methods}

Our study was carried out at the Nephrology Department of Aristide Le Dantec Hospital. It was a retrospective study which has been accomplished from January, 2010 to March, 2015. The records of patients that have diabetes as defined by the WHO and in whom the non-diabetic nephropathy diagnosis was suspected were included. The symptoms which enabled to suspect a NDN were:

Renal anomalies associated with a fresh diabetes;

Renal failure with rapid progress;

Diabetic retinopathy's absence;

Extra renal signs (cutaneous, digestive and articular) associated with an IRA;

Acute renal failure and biologic abnormalities;

Microscopic haematuria;

Inexploitable or incomplete patient records were not included.

For each patient, we collected epidemiological data, past medical history, clinico-paraclinical data, indications of Kidney biopsy (KB) and the histological 
lesion found.

The data was recorded on a computerized survey form using the Epi Info, 3.5.1 Version software.

Data analysis was performed with SPSS software 3.5 version.

The univariate analysis enabled to determine the distribution of each variable to be studied. The quantitative data are expressed as an average with the extremes.

The multivariate analysis with the ANOVA test (significant: if $\mathrm{P}$ less than 0.05 ) enabled to check the dependence between 2 or more variables.

\section{Results}

Out of a total of 34 biopsied diabetic patients' records, 12 had NDN as to say a prevalence of $35.3 \%$. The mean age was $49.88 \pm 13.62$ years with extremes of 17 and 72 years old. There were 19 women and 15 men and a sex-ratio of 0.78 .

Twelve patients had NDN and 22 had DN. We noted a feminine predominance in the group of patients with DN (sex-ratio of 0.69). In the group of patients with NDN, the distribution regarding both sexes was equal.

Twenty-three patients had past medical history of high blood pressure (67.60\%), 15 patients had type 1 diabetes (44.10\%) and 19 (55.90\%) had type 2. The Mean duration of diabetes was $12.53 \pm 4.7$ years for the whole population. Those with DN had a $15.32 \pm 5.59$ year and those in the NDN group had a $7.42 \pm$ 3.79 year.

Clinically, high blood pressure was noted in 18 patients (52.9\%). Among them, $10(63.6 \%)$ were in the DN group and 8 (66.6\%) in the NDN group.

The average systolic blood pressure was $140 \pm 23 \mathrm{mmHg}$ in our general population with $139.09 \pm 19.978 \mathrm{mmHg}$ for the ND group and $142.5 \pm 27.675 \mathrm{mmHg}$ for the NDN group. The various renal, extra-renal and biological manifestations are shown in Table 1.

The RB's indications were the presence of haematuria (27\%) and extra-renal signs (22\%). The other indications are listed in Figure 1.

The different lesions found in 22 cases were the DN (64.7\%) characterized by nodular glomerulosclerosis in KIMMELSTIEL WILSON and the NDN in 12 cases (35.3\%). The different NDN's lesions found are:

Focal and segmental glomerulosclerosis (16.60\%);

Fibro-proliferative endarteritis nephroangiosclerosis (16.60\%);

Myeloma cylinder tubulars (16.60\%);

Mutilating diffuse interstitial fibrosis and tubular inflammatory glomerular atrophy (16.60\%);

Endocapillary proliferation glomerulonephritis (8.30\%);

Glomerular deposits of amyloid (8.30\%);

Diffuse lupus nephritis and membraneous lupus nephritis ISN/RPS class IV + V (8.30\%);

Membranous nephropathy (8.30\%).

The NDN' percentage is shown in Figure 2. 
Predictive parameters of NDN's diagnosis were shorter diabetes duration $(\mathrm{P}=$ $0.0008)$, past medical history of hypertension $(P=0.0015)$, the absence of $D R(P$ $=0.005)$, and the microscopic haematuria $(\mathrm{P}=0.003)$. These different predictive factors described par $\mathrm{t}$ in Table 2.

Table 1. table of the various renal, extra-renal and biological clinical manifestations studied.

\begin{tabular}{ccccc}
\hline $\begin{array}{c}\text { Types of } \\
\text { manifestations }\end{array}$ & Studied parameters & $\begin{array}{c}\text { General } \\
\text { Population }\end{array}$ & ND & NDN \\
\hline \multirow{2}{*}{$\begin{array}{c}\text { Renal clinical } \\
\text { manifestations }\end{array}$} & $\begin{array}{c}\text { Tlomerular nephropathy syndrome } \\
\text { Tulo-interstitial nephropathy syndrome } \\
\text { Vascular nephropathy syndrome }\end{array}$ & $30(88.23 \%)$ & $21(70 \%)$ & $9(30 \%)$ \\
& cutaneous signs & $3(8.82 \%)$ & $1(33 \%)$ & $2(67 \%)$ \\
Extra-renal & Joint signs & 9 & 5 & 4 \\
manifestations & heart signs & 7 & 3 & 4 \\
& pulmonary signs & 1 & 0 & 1 \\
Biological & presence of diabetic retinopathy & 10 & 0 & 1 \\
manifestations & creatinine (mg/l) & $38.1 \pm 4$ & $35 \pm 3$ & $43.6 \pm 5$ \\
& Pu (g)/24 hours & 4.71 & 5.45 & 3.36 \\
& nephrotic syndrome & $22(64.67 \%)$ & $17(77.3 \%)$ & $5(32.3 \%)$ \\
& Glycohemoglobin & $24(64.4 \%)$ & $18(75 \%)$ & $6(25 \%)$ \\
& Microscopic Hematuria & $15(44.12 \%)$ & $9(60 \%)$ & $6(40 \%)$ \\
& fasting glucose (hyperglycemia) & $21(64 \%)$ & $14(66.7 \%)$ & $5(32.3 \%)$ \\
\hline
\end{tabular}

Table 2. NDN diagnosis's Predictive parameters.

\begin{tabular}{cc}
\hline NDN's predictive factors & $\mathrm{P}$ \\
\hline short duration of diabetes & 0.0008 \\
Past medical history of hypertension & 0.0015 \\
Absence of DR & 0.005 \\
Microscopic haematuria & 0.003 \\
\hline
\end{tabular}

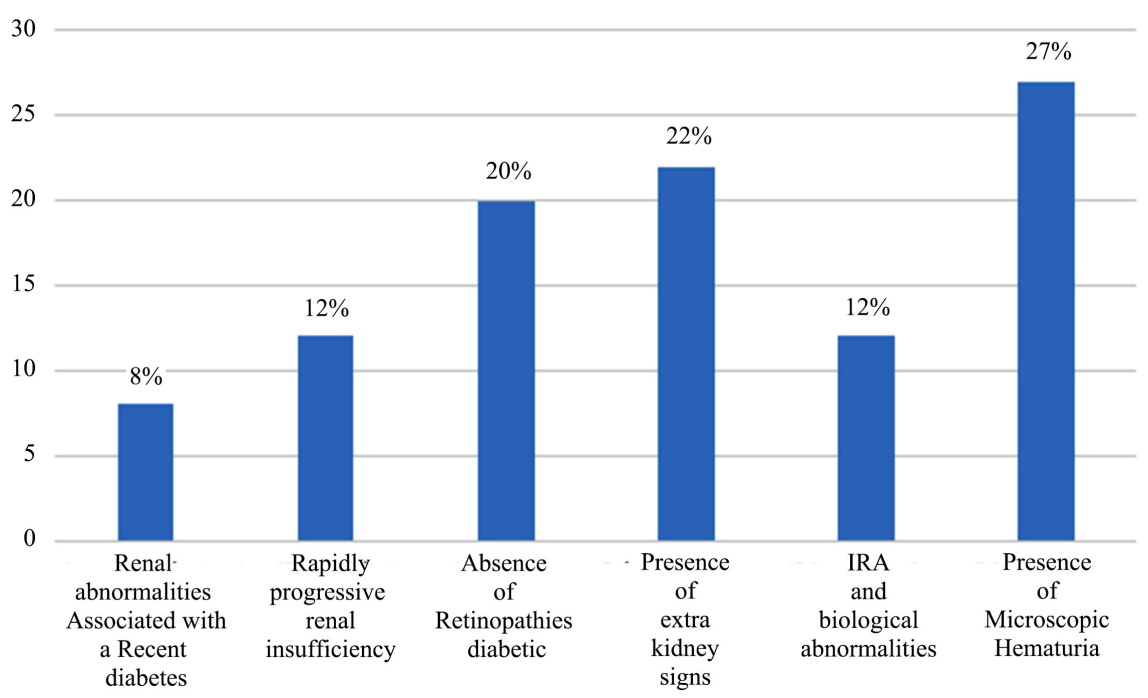

Figure 1. The Kidney biopsy puncture's indications (KBP). 


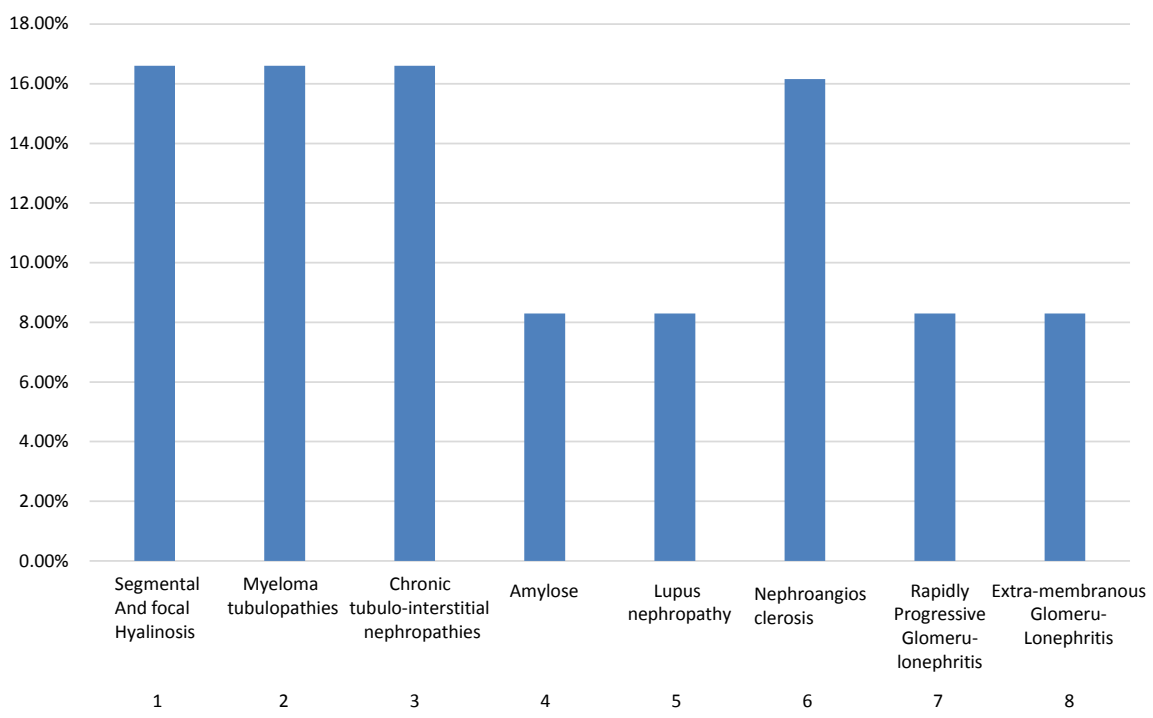

Figure 2. The different lesions of NDN.

\section{Discussion}

Classically diabetic nephropathy appears after 5 to 10 years of the disease evolution. However, the association of a shorter diabetes duration and the presence of renal abnormalities should be suggestive of NDN [5]. The duration of diabetes was shorter in the NDN's group with a median of 7.42 years compared to 15.32 years in the DN's group. Our results are identical to those of the literature this trend is found in the different series (Table 3). A shorter diabetes' duration was correlated with the occurrence of NDN $(\mathrm{P}=0.008)$ which is comparable to the results found in Morocco $(\mathrm{P}=0.022)$ [6].

In our series, high blood pressure was more common in the NDN's group (66.6\%) than the DN's group (63.6\%). This result was similar to that found in Zhou et al.'s series while in the Zajjari's series the NDN's group had less hypertension (16.7\%) compared to $80 \%$ for the DN's group. No statistically significant correlation was found between arterial high blood pressure and the NDN's occurrence $(\mathrm{P}=0.68)$ in our study, unlike the Moroccan's results $(\mathrm{P}=0.024)$ and China $(\mathrm{P}=0.001)[6][7]$.

Diabetic retinopathy is a microvascular complication of pathogenesis diabetes similar to DN [8]. According to Parving [3], all type 2 diabetic patients who have proteinuria with DR have also DN. The presence of proteinuria without DR gives DN in $50 \%$ of cases [3]. In our study all patients with DR have DN and $90 \%$ of patients without DR had NDN. This trend is similar to that found in the Zajjari series [6], all patients with DR had DN, and $60 \%$ of patients without $\mathrm{RD}$ had NDN. These results suggest that the presence of RD is a marker of DN and then its absence is a predictive factor of NDN.

Haematuria is an unusual DN's manifestation. It is the expression of several NDN. In Wong's study, the association of proteinuria or haematuria with the absence of DR gave a NDN with a positive predictive value of $94 \%$ [8]. In our study haematuria was present in almost similar rates in both groups: NDN 
(44.1\%) ND (40.9\%). These results were not consistent with data from the literature showing a predominance of haematuria in the NDN with $83.3 \%$ and $68 \%$ respectively in the Zhou [7] and Zajjari's [6] series.

In the diabetic kidney biopsy series, the NDN's prevalence varied between $10 \%$ to $85 \%$ [9] [10]; this difference depends on Kidney biopsy's criterion indication and the studied population [11]. In our study, the prevalence of NDN was $35.3 \%$. This prevalence is similar to that of Zajjari. The different NDN's prevalence are listed in Table 4.

The main NDN's lesion found in our study compared with others are reported in Table 5.

Table 3. Longstanding of the diabetes in the NDN and the DN.

\begin{tabular}{clc}
\hline & \multicolumn{2}{c}{ Longstanding of the diabetes (years) } \\
\cline { 2 - 3 } Authors & $\mathrm{DN}$ & NDN \\
\hline $\begin{array}{c}\text { Our study: } 34 \text { patients } \\
\text { (Dakar) }\end{array}$ & 15.32 & 7.42 \\
$\begin{array}{l}\text { Y. Zajjari et al. } \\
\text { Marocco [6] }\end{array}$ & 15.5 & 4.5 \\
$\begin{array}{c}\text { Jianhui Zhou et al. } \\
\text { (China) [7] }\end{array}$ & 7.3 & 2.1 \\
\hline
\end{tabular}

Table 4. The prevalence of patients with a NDN.

\begin{tabular}{cc}
\hline Auteurs & The prevalence of patients with a NDN (\%) \\
\hline Our study (34 patients) & 35.3 \\
$\begin{array}{c}\text { Y. Zajjari et al. } \\
\text { Marocco (16 patients) [6] }\end{array}$ & 37.5 \\
Jianhui Zhou et al. \\
(China) (113 patients) [7]
\end{tabular}

Table 5. NDN's summary and comparative table according to the series.

\begin{tabular}{|c|c|c|c|}
\hline & & \multicolumn{2}{|c|}{ AUTHORS } \\
\hline NDN found (\%) & Our serie Senegal & $\begin{array}{l}\text { Y. Zajjari et al. } \\
\text { Marocco [6] }\end{array}$ & $\begin{array}{c}\text { Zhou et al. China } \\
\text { [7] }\end{array}$ \\
\hline SIN & 16.6 & 0 & 6 \\
\hline Myeloma tubulopathy & 16.6 & 16.1 & 0 \\
\hline Nephropathy at IgA & 0 & 50.7 & 34 \\
\hline Lupus & 8.31 & 0 & 2 \\
\hline NICT & 16.6 & 0 & 0 \\
\hline $\begin{array}{c}\text { Extra capillary } \\
\text { glomerulonephritis (ECGN) }\end{array}$ & 8.31 & 0 & 20 \\
\hline $\begin{array}{c}\text { Membranoproliferative } \\
\text { glomerulonephritis (MPGN) }\end{array}$ & 0 & 0 & 1 \\
\hline
\end{tabular}




\section{Continued}

\begin{tabular}{cccc}
\hline Renal amylose & $\mathbf{8 . 3 1}$ & 0 & 7 \\
Segmental and focal hyalinosis & 16.6 & 0 & 4 \\
Mineral glomerular lesion (MGL) & 0 & 16.1 & 4 \\
$\begin{array}{c}\text { Extra membranous } \\
\text { glomerulopathy (EMG) }\end{array}$ & 8.31 & 16.1 & 22 \\
\hline
\end{tabular}

\section{Limits}

The monocentric character of this study makes it difficult to apply its results on a large scale and the poorly maintained medical records, many of which were unusable, were an obstacle to a better assessment of the occurrence of NND

\section{Conclusion}

Non-diabetic nephropathy (NDN) is frequent in our regions. Our data show that kidney injury in a diabetic is not always diabetic nephropathy. The diabetic retinopathy's absence (DR) and the presence of nephropathy's symptoms should be suggestive of NND. The Kidney biopsy (KB) is often needed in order to adopt an effective management.

\section{Conflicts of Interest}

None.

\section{References}

[1] Held, P.J., et al. (1990) The United States Renal Data System's 1990 Annual Data Report: An Introduction. American Journal of Kidney Diseases, 16, 1-106.

[2] Oslerby, R., et al. (1990) Glomerular Structure and Function in Diabetes Mellitus. Diabetes, 39, 1057-1060. https://doi.org/10.2337/diab.39.9.1057

[3] Parving, H.H., Osterby, R. and Ritz, E. (2000) Diabetic Nephropathy. In: Brenner, B.M., Ed., Brenner \& Rector's the Kidney, WB Saunders, Philadelphia, 1731-1760.

[4] Viberti, G.C., Marshall, S., Beech, R., Brown, V., Derben, P., Higson, N., Home, P., Keen, H., Plant, M. and Walls, J. (1996) Report on Renal Disease in Diabetes. Diabetic Medicine, 13, S6-S12.

[5] Dussol, B. and Berland, Y. (2006) What Do the Major Clinical Trials of Cardiovascular and Renal Prevention in Patients with Type 2 Diabetes Hypertensive. Néphrologie \& Thérapeutique, 2, 51-74.

[6] Zajjari, Y., Benyahia, M., Montasser Ibrahim, D., Kassouati, J., Maoujoud, W., El Guendouz, F. and Oualim, Z. (2012) Non-Diabetic Nephropathy in Type 2 Diabetic Patients at the Mohammed V Military Hospital in Rabat (Morocco). EMHJ, 18, 620-623.

[7] Jianhui Zhou, et al. (2008) A Differential Diagnosis Model of Diabetic Nephropathy and Non-Diabetic Renal Diseases. Nephrology Dialysis Transplantation, 23, 1940-1945. https://doi.org/10.1093/ndt/gfm897

[8] Wong, T.Y., et al. (2002) Renal Outcome in Type 2 Diabetic Patients with or without Coexisting Nondiabetic Nephropathies. Diabetes Care, 25, 900-905. https://doi.org/10.2337/diacare.25.5.900 
[9] Lee, E.Y., Chung, C.H. and Choi, S.W. (1999) Non-Diabetic Renal Disease in Patients with Non-Insulin Dependent Diabetes Mellitus. Yonsei Medical Journal, 40, 321-326. https://doi.org/10.3349/ymj.1999.40.4.321

[10] Olsen, S. and Mogensen, C.E. (1996) How Often Is NIDDM Complicated with Non-Diabetic Renal Disease? An Analysis of Renal Biopsies and the Literature. Diabetologia, 39, 1638-1645. https://doi.org/10.1007/s001250050628

[11] Bertani, T., et al. (1986) Superimposed Nephritis: A Separate Entity among Glomerular Diseases? American Journal of Kidney Diseases, 7, 205-212. 